\title{
Residue patterns of indoxacarb and pyridalyl in treated cauliflower
}

\author{
Ji-Young Yoon ${ }^{1}$, Jae-Hun Park ${ }^{1}$, Hye-Ree Moon ${ }^{1}$, Guk-Tak Han $^{2}$, Kyu-Seung Lee $^{1^{*}}$ \\ ${ }^{1}$ Department of Bio-Environmental Chemistry, Chungnam National University, Daejeon, Republic of Korea; \\ *Corresponding Author: kslee@cnu.ac.kr \\ ${ }^{2}$ National Agriculture Product Quality Management Service, Chungnam Division Branch Office, Daejeon, Republic of Korea
}

Received 31 January 2013; revised 5 March 2013; accepted 15 March 2013

\begin{abstract}
The biological half-life and final residue levels of indoxacarb and pyridalyl were determined in cauliflower over a 10-day cultivation period following applications of a standard (100 g a.i.'ha ${ }^{-1}$ and $200 \mathrm{~g}$ a.i. $\mathrm{ha}^{-1}$, respectively) and double dose $\left(200 \mathrm{~g}\right.$ a.i. $\mathrm{ha}^{-1}$ and $400 \mathrm{~g}$ a.i. $\mathrm{ha}^{-1}$, respectively). The residue levels were analyzed by gas chromatography with recovery ranging from $92.1 \%$ to $109.7 \%$. The biological half-lives of indoxacarb and pyridalyl were 6.33 and 7.74 days for the standard dose, and 6.26 and 7.44 days for the double dose, respectively. The initial and persisting concentrations of indoxacarb and pyridalyl were all below the Korean maximum residue limits for broccoli of $1.0 \mathrm{mg} \cdot \mathrm{kg}^{-1}$ and 3.0 $\mathrm{mg} \cdot \mathrm{kg}^{-1}$, respectively.
\end{abstract}

Keywords: Biological Half-Life; Cauliflower; Indoxacarb; Pyridalyl; Residue

\section{INTRODUCTION}

Cauliflower (Brassica oleracea var. botrytis L.) is an important vegetable crop grown extensively in Asia, Europe, and America. It is low in fat and high in dietary fiber, folate, water, and vitamin $\mathrm{C}$, has a very high nutritional density, and contains glucosinolates (including sulfurophane), which may improve the liver's ability to detoxify carcinogenic substances. A high intake of cauliflower has been found to reduce the risk of aggressive prostate cancer [1]. One of the major constraints in commercial growth of this crop is the heavy damage caused to its leaves and heads by insect pests. The intensive insecticide applications required to protect this plant against insects, are likely to leave residues on heads, which may be hazardous to consumers [2].

Indoxacarb, methyl (S)- $N$-[7-chloro-2,3,4a,5-tetrahydro4a-methoxycarbonyl)indeno[1,2-e][1,3,4]oxadiazin-2- ylcarbonyl]-4'-(trifluoromethoxy)carbanilate (Figure 1(a)), is an indeno-oxadiazine insecticide that is a broad spectrum, highly effective, nonsystemic, and synthetic organophosphate replacement insecticide. It is typically used on vegetables, tree fruit, vines, cotton, corn, and other crops to control lepidopteran pests and selected insect pests with sucking mouthparts [3]. A key feature of this compound is its novel bioactivation, which blocks off the insects' voltage-gated metabolites. This mode of action differentiates these oxadiazines from any other comercial insecticides [4].

Pyridalyl, 2,6-dichloro-4-(3,3-dichloroallyloxy)phenyl 3-[5-9trifluoromethyl]-2-pyridyloxy]propyl ether (Figure 1(b)), is a novel insecticide that has a phenoxy pyridaloxy derivative structure and provides excellent control against lepidopteran and thysanoperan pests on cotton, vegetables, and fruits without generating phytotoxic effects. It is also effective on pests that have developed a resistance to existing insecticides, indicating a different mode of action from any other conventional insecticide $[5,6]$.

As cauliflower is not a popular food item in Korea, good agricultural practice (GAP) standards and maximum residue limit (MRL) values for cauliflower were not available. For this reason, field treatments were carried out according to GAP standards for broccoli. The aim of this study was to determine the biological half-life and residue patterns of two pesticides, indoxacarb and pyridalyl, in cauliflower during cultivation. The final residue levels at harvest were predicted after both pesticides were sprayed two and three times, at 7- and 10-day spray intervals, to determine the exact dose, preharvest interval (PHI), and harvest time that minimized the effects of the residues.

\section{MATERIALS AND METHODS}

\subsection{Chemicals}

Analytical standard indoxacarb (99.5\% pure) and pyridalyl (98.5\% pure) were purchased from Dr. Ehrenstorfer 
<smiles>COC(=O)N(C(=O)N1COC2(C(=O)OC)Cc3cc(Cl)ccc3C2=N1)c1ccc(OC(F)(F)F)cc1</smiles>

(a)<smiles>FC(F)(F)c1ccc(OCCCOc2c(Cl)cc(OCC=C(Cl)Cl)cc2Cl)nc1</smiles>

(b)

Figure 1. Chemical structures of (a) indoxacarb and (b) pyridalyl.

GmbH (Augsburg, Germany). Stock (1000 $\mathrm{mg} \cdot \mathrm{L}^{-1}$ ) and working standard solutions were prepared in acetone and used as external standards throughout the study. A florisil solid-phase extraction (SPE) cartridge $(1000 \mathrm{mg} / 6 \mathrm{~mL})$ was purchased from Phenomenex (Torrance, CA, USA). All solvents were of pesticide residue grade and obtained from Merck (Darmstadt, Germany).

\subsection{Field Treatment and Sampling}

The experimental field was located under a greenhouse in Yesan-eup, Yesan-gun, Chungcheongnam-do, Korea. Field-grown cauliflower was divided into 15 of $10-\mathrm{m}^{2}$ plots, including three experimental replicates with a randomized complete block design. Treatments were carried out with the following commercial products according to the GAP standard for broccoli in Korea: Ammate WP (10\% indoxacarb) at a standard single dose of

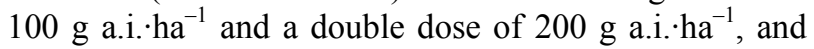
Pleo EW (10\% pyridalyl) at a standard single dose of 200 $\mathrm{g}$ a.i. $\mathrm{ha}^{-1}$ and a double dose of $400 \mathrm{~g}$ a.i. $\cdot \mathrm{ha}^{-1}$. Pesticides were applied at 7-day intervals using a rechargeable battery sprayer (KS-PK 2000; Kwang Sung, Daejeon, Korea) with a spray volume of $0.4 \mathrm{~L} \cdot \mathrm{m}^{-2}$. The control plot was maintained at a safe distance. After the final spraying, representative samples ( 8 - 9 cauliflower heads) were collected at $0(2 \mathrm{~h}), 1,2,3,5,7,9$, and 10 days, and brought to the laboratory in polyethylene bags with minimal finger contact. Samples of chopped cauliflower heads were mixed and quartered and then blended and stored in a freezer at $-20^{\circ} \mathrm{C}$ until analysis.

Meteorological data were continuously recorded with a DT-172 temperature and humidity datalogger (CEM, Guangdong, China). During the experimental period, the average relative humidity ranged from $53.9 \%$ to $84.5 \%$, with maximum and minimum average daily temperatures of $17.3^{\circ} \mathrm{C}$ and $5.6^{\circ} \mathrm{C}$, respectively.

\subsection{Extraction and Partitioning}

A 20-g sample was placed into an Erlenmeyer flask with $100 \mathrm{~mL}$ acetone and shaken for $30 \mathrm{~min}$ on a mechanical shaker (Vision Scientific Co., Ltd., Daejeon, Korea). The sample was then filtered under vacuum through a Buchner funnel. The container and filter cakes were washed with $30 \mathrm{~mL}$ acetone and the rinsate was combined with the previous filtrate. The filtrate was concentrated to about $20 \mathrm{~mL}$ using a vacuum rotary evaporator and transferred to a 1-L separatory funnel. After adding $300 \mathrm{~mL}$ distilled water and $50 \mathrm{~mL}$ saturated sodium chloride solution to the above extract, partitioning was carried out twice with $70-\mathrm{mL}$ portions of $n$-hexane. The hexane layer was collected over $30 \mathrm{~g}$ of anhydrous sodium sulfate and evaporated to dryness on a vacuum rotary evaporator at $40^{\circ} \mathrm{C}$. The dried extract was dissolved in $3 \mathrm{~mL} n$-hexane for cleanup.

\subsection{Cleanup}

The florisil SPE cartridge was preconditioned with 5 $\mathrm{mL} n$-hexane and the sample extract from the partitioning step was then added. To remove impurities, the SPE cartridge was washed with $5 \mathrm{~mL} n$-hexane and eluted with $15 \mathrm{~mL}$ acetone/ $n$-hexane $(20: 80, \mathrm{v} / \mathrm{v})$ for indoxacarb and $30 \mathrm{~mL}$ acetone/ $n$-hexane $(20: 80, \mathrm{v} / \mathrm{v})$ for pyridalyl. The eluate was evaporated to dryness in a vacuum rotary evaporator at $40^{\circ} \mathrm{C}$ and the residue was redissolved in 4 $\mathrm{mL}$ acetone for gas chromatography with an electron capture detector (ECD).

\subsection{Confirmation of the Residue}

A gas chromatograph (model 6890; Agilent, Santa Clara, CA, USA) equipped with an ECD and DB-5 column (30 $\mathrm{m} \times 0.25 \mathrm{~mm}$ i.d., $0.25 \mu \mathrm{m}$ film thickness) was used to determine the level of pesticide residue. A $1-\mu \mathrm{L}$ sample was injected in split mode (28:1) and the injector and detector temperatures were $250^{\circ} \mathrm{C}$ and $320^{\circ} \mathrm{C}$, respectively. Oven temperature programming was initialized with a $2 \mathrm{~min}$ hold at $190^{\circ} \mathrm{C}$, and then the temperature was increased at $10^{\circ} \mathrm{C} \cdot \mathrm{min}^{-1}$ to $300^{\circ} \mathrm{C}$, where it was finally held for $10 \mathrm{~min}$, giving a total run time of $22 \mathrm{~min}$. Ultrapure nitrogen was used as the carrier gas with a flow rate of $1 \mathrm{~mL} \cdot \mathrm{min}^{-1}$, and the retention times of indoxacarb and pyridalyl were 15.87 and $14.28 \mathrm{~min}$, respectively.

\subsection{Validation of the Analytical Method}

Recovery studies were performed with fortification levels of $0.02 \mathrm{mg} \cdot \mathrm{kg}^{-1}[10 \times$ limit of quantification (LOQ)] and $0.1 \mathrm{mg} \cdot \mathrm{kg}^{-1}(50 \times \mathrm{LOQ})$, obtained from control samples. Three replicates were analyzed at each fortification level. Average recoveries were 92.1\% - 109.7\%, 
whereby the coefficient of variation was within $10 \%$, which is generally considered satisfactory for residue quantification. Results of the recovery studies are presented in Table 1.

\subsection{Statistical Analysis}

The residue results were the means from three replicates of each treatment and all data were analyzed applying simple descriptive statistics such as the mean and standard deviation using Microsoft Excel.

\section{RESULTS AND DISCUSSION}

Residues of the pesticides were determined in samples by comparing the area of the concentration peak with that of the external standard method. A six-point calibration curve from 0.01 to $2 \mathrm{mg} \cdot \mathrm{kg}^{-1}$ was constructed for quantitative analysis. The detector responses of two pesticides were linear throughout the entire range of concentrations, with a correlation coefficient $\left(R^{2}\right)$ of $0.999^{* * *}$ shown in Figure 2. Kinetic equations for the pesticides were calculated from a simple first-order kinetic equation, where $C_{t}$ is the concentration $\left(\mathrm{mg} \cdot \mathrm{kg}^{-1}\right)$ at time $t$ (days) after application, $C_{0}$ is the initial concentration $\left(\mathrm{mg} \cdot \mathrm{kg}^{-1}\right)$, and $k$ is the first-order rate constant.

$$
\begin{aligned}
& C_{t}=C_{0} e^{-k t} \\
& \mathrm{DT}_{50}=\ln 2 / k
\end{aligned}
$$

Table 1. Recovery and limit of quantification of the analytical method for both pesticides in cauliflower.

\begin{tabular}{cccc}
\hline \multirow{2}{*}{$\begin{array}{c}\text { Fortification } \\
\left(\mathrm{mg} \cdot \mathrm{kg}^{-1}\right)\end{array}$} & \multicolumn{2}{c}{ Recovery $\pm \mathrm{CV}(\%)$} & $\begin{array}{c}\text { LOQ } \\
\left(\mathrm{mg} \cdot \mathrm{kg}^{-1}\right)\end{array}$ \\
\cline { 2 - 3 } 0.02 & $108.1 \pm 1.6$ & $101.0 \pm 5.3$ & 0.002 \\
0.1 & $97.1 \pm 1.4$ & $92.8 \pm 1.8$ & \\
\hline
\end{tabular}

$\mathrm{CV}$, coefficient of variation; $\mathrm{LOQ}$, limit of quantification.

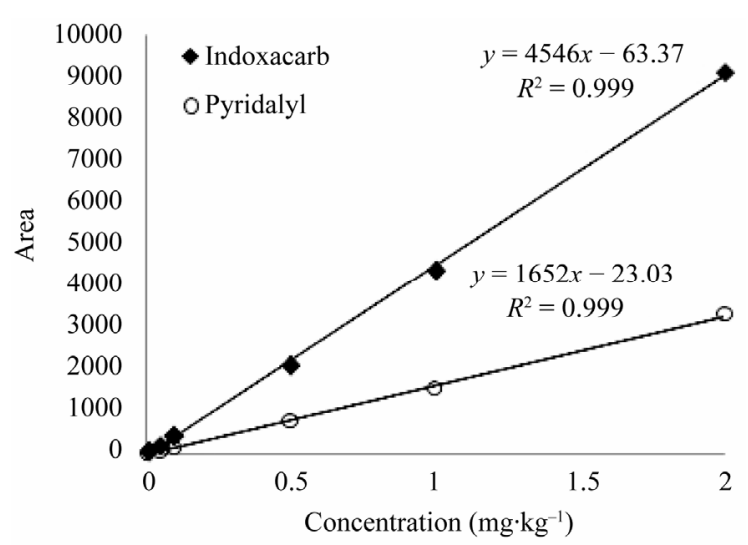

Figure 2. Linearity calibration curve at concentrations of $0.01-2 \mathrm{mg} \cdot \mathrm{kg}^{-1}$.

\subsection{Indoxacarb}

Initial $(2 \mathrm{~h})$ deposits of indoxacarb on cauliflower were 0.29 and $0.58 \mathrm{mg} \cdot \mathrm{kg}^{-1}$ for the recommended and double doses, respectively. Ten days after application, the remaining residues were 0.07 and $0.16 \mathrm{mg} \cdot \mathrm{kg}^{-1}$, respectively. Hence, $75.86 \%$ and $72.41 \%$ of the initial residue levels, respectively, had dissipated. Figure 3 shows the changes in indoxacarb residue at eight sample times 0 - 10 days after spraying. The kinetics of indoxacarb can be described by the following equations: $y=$ $0.3330 e^{-0.1095 t}\left(R^{2}=0.7187^{* *}\right)$ and $y=0.6201 e^{-0.1108 t}\left(R^{2}\right.$ $\left.=0.9185^{* * *}\right)$. The initial and persisting concentrations of indoxacarb for the recommended and double doses were all below the Korean MRL for broccoli of $1.0 \mathrm{mg} \cdot \mathrm{kg}^{-1}$, while it took 4.66 and 10.21 days, respectively, for the dissipation of residues below the MRL of $0.2 \mathrm{mg} \cdot \mathrm{kg}^{-1}$ set in the Codex Alimentarius Regulations for cauliflower. The biological half-lives of indoxacarb in cauliflower at the recommended and double doses were 6.33 and 6.26 days, respectively. The results were different from those of Takkar et al. [1] who reported a half-life of 1.12 and 1.31 days for cauliflower following indoxacarb (14.5\% SC) applications of 52.2 and $104.4 \mathrm{~g}$ a.i. $\mathrm{ha}^{-1}$, respectively. This faster dissipation rate could be due to differences in the experimental design and environmental affects arising from the use of an open field site at the Vegetable Research Farm (Punjab Agricultural University, Ludhiana, India). Lee et al. [7] reported that under greenhouse conditions, initial deposits of indoxacarb applied to Chinese cabbage (Brassica chinensis L.) at a rate of $60 \mathrm{~g}$ a.i.ha ${ }^{-1}$ and $120 \mathrm{~g}$ a.i. $\mathrm{ha}^{-1}$ were 1.40 and $2.95 \mathrm{mg} \cdot \mathrm{kg}^{-1}$, and the biological half-lives were 3.4 and 3.3 days, respectively. Although the doses used in the cauliflower experiments reported here were higher than the doses used in the Chinese cabbage study by Lee et al. [7], the initial deposits in Chinese cabbages were much higher than in cauliflower. This might be a consequence of the difference in vegetable surface area. As the cauliflower head was only edible part, the thick leaves that

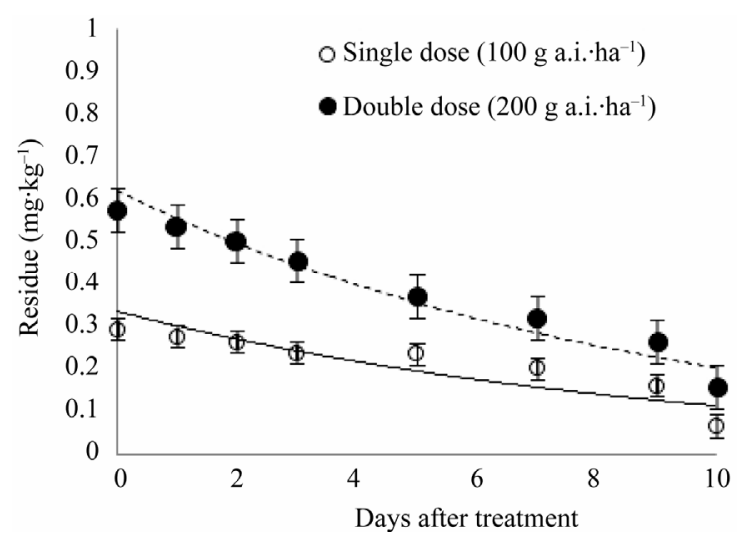

Figure 3. Dissipation of indoxacarb in cauliflower. 
surrounded the head were discarded in this study, while the whole plant of the Chinese cabbage was used by Lee et al. [7]. The faster dissipation rate in Chinese cabbages might also partially due to its higher growth rate in comparison with cauliflower, which causes a rapid growth dilution effect in pesticide concentrations. The growth rates of Chinese cabbage and cauliflower heads were $182.03 \pm 1.71 \%$ and $97.8 \pm 1.53 \%$, respectively.

The final residue levels were compared when indoxacarb was sprayed two and three times at $100 \mathrm{~g}$ a.i. $\mathrm{ha}^{-1}$ with a spray interval of 7 and 10 days. Indoxacarb residues according to the level of application are shown in Figure 4. Predicted values were calculated based on the initial amount applied and the coefficient of regression [8]. After spraying with $200 \mathrm{~g}$ a.i. $\cdot \mathrm{ha}^{-1}\left(100 \mathrm{~g}\right.$ a.i. $\left.\cdot \mathrm{ha}^{-1} \times 2\right)$ and $300 \mathrm{~g}$ a.i. $\mathrm{ha}^{-1}\left(100 \mathrm{~g}\right.$ a.i. $\left.\mathrm{ha}^{-1} \times 3\right)$ at a 7 -day spray interval, predicted residues were $0.35,0.23$, and 0.11 $\mathrm{mg} \cdot \mathrm{kg}^{-1}$, and $0.40,0.26$, and $0.12 \mathrm{mg} \cdot \mathrm{kg}^{-1}$ at 3,7 , and 14 days PHI, respectively. After spraying with $200 \mathrm{~g}$ a.i. $\mathrm{ha}^{-1}\left(100 \mathrm{~g}\right.$ a.i.ha $\left.{ }^{-1} \times 2\right)$ and $300 \mathrm{~g}$ a.i. $\mathrm{ha}^{-1}(100 \mathrm{~g}$ a.i. $\left.\mathrm{ha}^{-1} \times 3\right)$ at a 10 -day spray interval, predicted residues were $0.32,0.21$, and $0.10 \mathrm{mg} \cdot \mathrm{kg}^{-1}$, and $0.35,0.22$, and $0.10 \mathrm{mg} \cdot \mathrm{kg}^{-1}$ at 3,7 , and 14 days PHI, respectively. From this prediction, the indoxacarb residue in cauliflower was expected to be above the MRL of $0.2 \mathrm{mg} \cdot \mathrm{kg}^{-1}$ up to 8 and 9 days after spraying with $200 \mathrm{~g}$ a.i. $\mathrm{ha}^{-1}(100$ g a.i. $\left.\mathrm{ha}^{-1} \times 2\right)$ and $300 \mathrm{~g}$ a.i. $\mathrm{ha}^{-1}\left(100 \mathrm{~g} \cdot \mathrm{ha}^{-1} \times 3\right)$ for a 7-day spray interval and up to 7 and 8 days after spraying with $200 \mathrm{~g}$ a.i. $\mathrm{ha}^{-1}\left(100 \mathrm{~g}\right.$ a.i. $\left.\mathrm{ha}^{-1} \times 2\right)$ and $300 \mathrm{~g}$ a.i. $\mathrm{ha}^{-1}\left(100 \mathrm{~g} \cdot \mathrm{ha}^{-1} \times 3\right)$ for a 10 -day spray interval, respectively. Indoxacarb is registered for use on cauliflower in France, Germany, Denmark, and Italy at an application level of $26 \mathrm{~g}$ a.i.ha ${ }^{-1}$ with a PHI of 3 days and no more than three applications per harvest. In Australia and New Zealand, its use is registered for an application level of $75 \mathrm{~g}$ a.i. ha ${ }^{-1}$ with a PHI of 7 days and no more than four applications per harvest [9]. The present study therefore suggests that under greenhouse conditions, the recommended single dose $\left(100 \mathrm{~g}\right.$ a.i. $\left.\mathrm{ha}^{-1}\right)$ applied by the farmer in the field should be lower, or the PHI should be longer.

\subsection{Pyridalyl}

Initial $(2 \mathrm{~h})$ deposits were 0.43 and $0.84 \mathrm{mg} \cdot \mathrm{kg}^{-1}$ for the recommended and double doses, respectively. Ten days after application, the remaining residues were 0.12 and $0.30 \mathrm{mg} \cdot \mathrm{kg}^{-1}$; i.e., $72.09 \%$ and $64.29 \%$ of the initial residue levels had dissipated. Figure 5 shows the changes in pyridalyl residue for eight sample times 0 - 10 days after spraying. The kinetics of pyridalyl can be described by the following equations: $y=0.4715 e^{-0.0896 t}\left(R^{2}\right.$ $\left.=0.6859^{*}\right)$ and $y=0.8379 e^{-0.0932 t}\left(R^{2}=0.9719^{* * *}\right)$. All the residues at the recommended and double doses were below the Korean MRL for broccoli of $3.0 \mathrm{mg} \cdot \mathrm{kg}^{-1}$. The

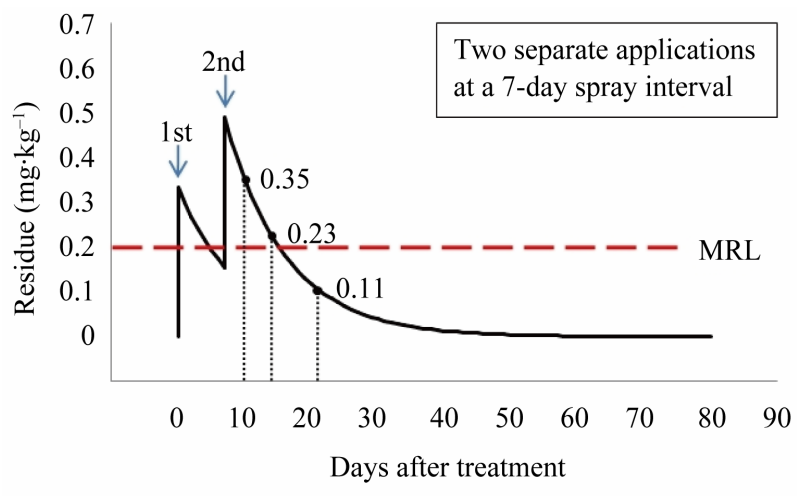

(a)

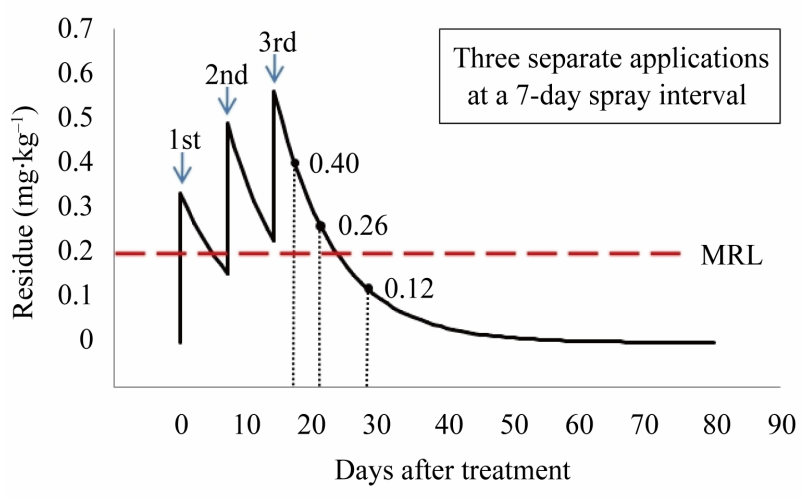

(b)

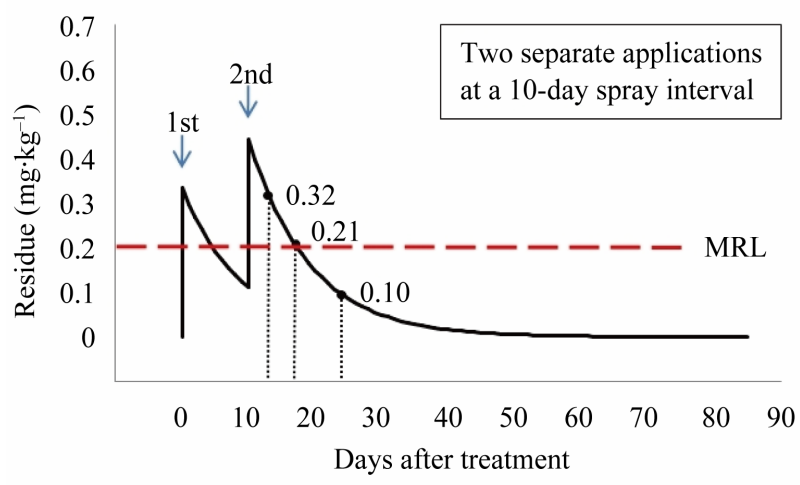

(c)

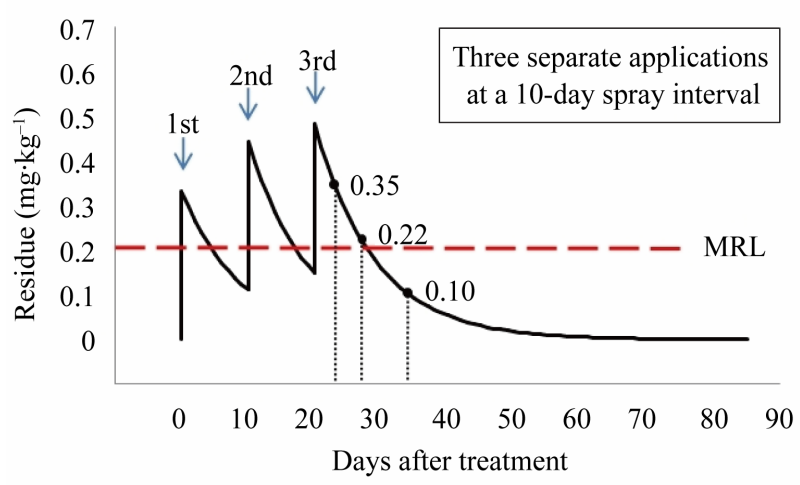

(d)

Figure 4. Predicted final residue levels of indoxacarb as a function of the amount applied (MRL: maximum residue limit). 


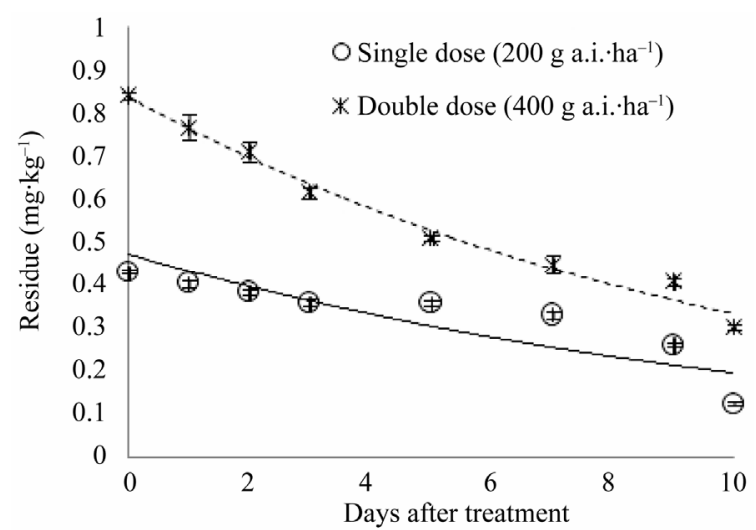

Figure 5. Dissipation of pyridalyl in cauliflower.

residue levels can only be compared with MRLs set by individual countries' due to the absence of MRLs set by bodies such as the European Union or Food and Agriculture Organization/World Health Organization. Japan has set a level of $2 \mathrm{mg} \cdot \mathrm{kg}^{-1}$ as the MRL for broccoli, which is higher than the levels of pyridalyl residues on cauliflower measured in this study. The biological halflives of pyridalyl in cauliflower for the recommended and double doses were 7.74 and 7.44 days, respectively. To the best of our knowledge, no other information regarding pyridalyl residues on cauliflower has been published. However, Svetlana et al. [10], who studied the dissipation of pyridalyl on spring onions and strawberries following an application of $238 \mathrm{~mL}$ a.i. $\mathrm{ha}^{-1}$, reported initial deposits of less than $3 \mathrm{mg} \cdot \mathrm{kg}^{-1}$, which declined to $1 \mathrm{mg} \cdot \mathrm{kg}^{-1}$ in 7 days, with half-lives of 0.27 and 5.99 days, respectively. The higher residues on strawberries were probably due to the difference in surface area. Spray retention on onion leaves can also be difficult because of the vertical nature of the plant [10].

The final residue levels were compared after pyridalyl has been applied two and three times at a spray interval of 7 and 10 days; the predicted residues are given in Figure 6. After spraying with $400 \mathrm{~g}$ a.i. $\mathrm{ha}^{-1}(200 \mathrm{~g}$ a.i. $\left.\mathrm{ha}^{-1} \times 2\right)$ and $600 \mathrm{~g}$ a.i. $\mathrm{ha}^{-1}\left(200 \mathrm{~g}\right.$ a.i. $\left.\mathrm{ha}^{-1} \times 3\right)$ with a 7-day spray interval, predicted residues were $0.55,0.39$, and $0.21 \mathrm{mg} \cdot \mathrm{kg}^{-1}$, and $0.64,0.44$, and $0.23 \mathrm{mg} \cdot \mathrm{kg}^{-1}$ at 3 , 7 , and 14 days PHI, respectively. After spraying with $400 \mathrm{~g}$ a.i. $\mathrm{ha}^{-1}\left(200 \mathrm{~g} \mathrm{a.i.} \cdot \mathrm{ha}^{-1} \times 2\right)$ and $600 \mathrm{~g} \mathrm{a.i.ha^{-1 }}$ $\left(200 \mathrm{~g}\right.$ a.i. $\left.\cdot \mathrm{ha}^{-1} \times 3\right)$ at a 10 -day spray interval, predicted residues were $0.51,0.36$, and $0.19 \mathrm{mg} \cdot \mathrm{kg}^{-1}$, and 0.57 , 0.40 , and $0.19 \mathrm{mg} \cdot \mathrm{kg}^{-1}$ at 3,7 , and 14 days PHI, respectively. To remove the toxic effects of pesticide residues, the present study on cauliflower cultivated in a greenhouse indicates that the recommended pyridalyl dose, according to the GAP standard of Korea for broccoli, is appropriate for the application of the insecticide on cauliflower. If necessary, a lower MRL of $2.0 \mathrm{mg} \cdot \mathrm{kg}^{-1}$ can be achieved.

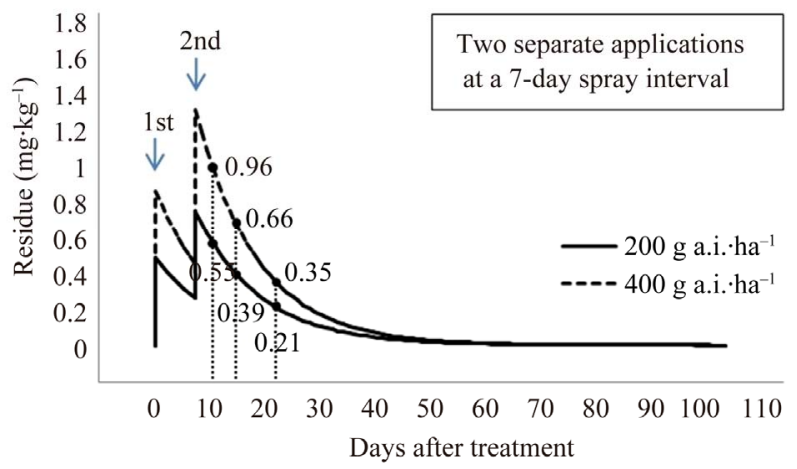

(a)

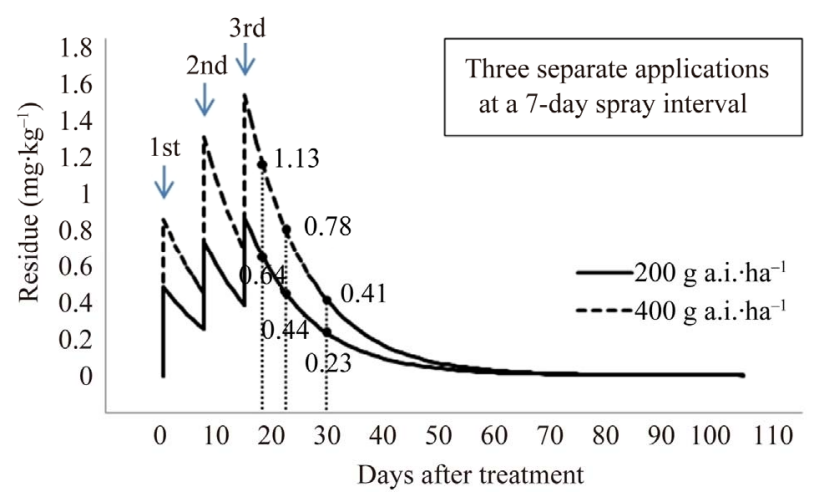

(b)

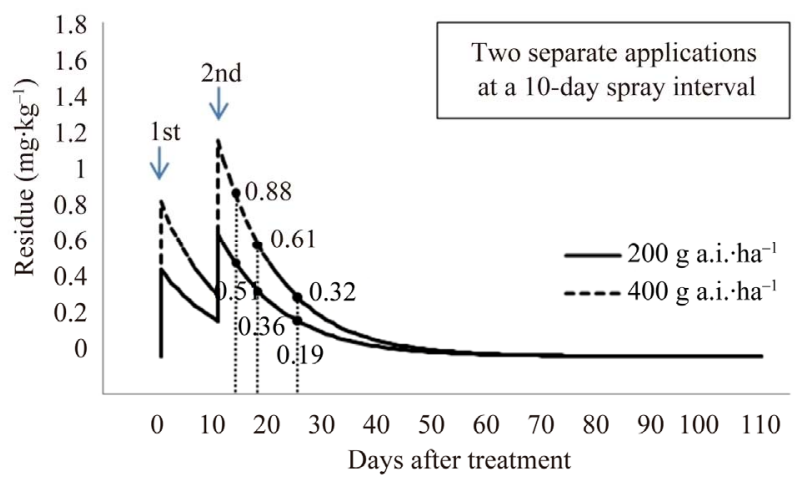

(c)

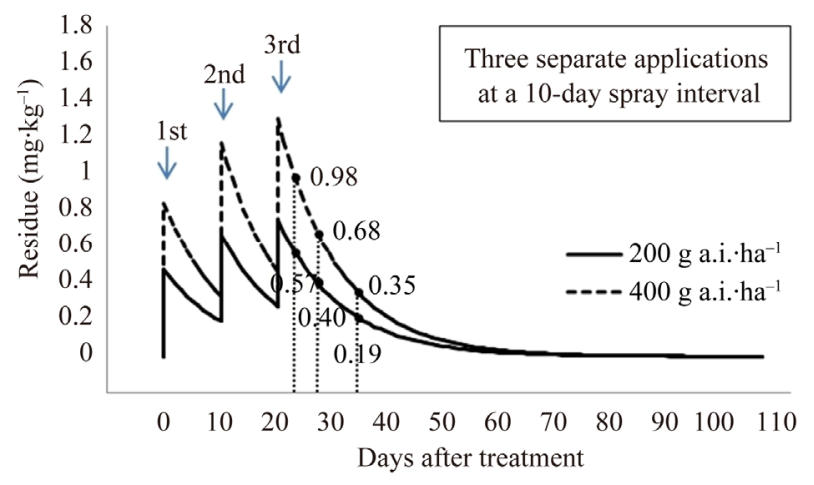

(d)

Figure 6. Predicted final residue levels of pyridalyl as a function of the amount applied. 


\section{ACKNOWLEDGEMENTS}

This study was financially supported by the National Agricultural Products Quality Management Services, Republic of Korea.

\section{REFERENCES}

[1] Takkar, R., Sahoo, S., Singh, G., Mandal, K., Battu, R. and Singh, B. (2011) Persistence of indoxacarb on cauliflower (Brassica oleracea var. botrytis. L.) and its risk assessment. American Journal of Analytical Chemistry, 2, 69-76. doi:10.4236/ajac.2011.228126

[2] Raina, A. and Raina, M. (2008) Dissipation of chlorpyriphos on cauliflower (Brassica oleracea L. var. botrytis). Pesticide Research Journal, 20, 263-265.

[3] Urvashi, Jyot, G., Sahoo, S.K., Kaur, S., Battu, R.S. and Singh, B. (2012) Estimation of indoxacarb residues by QuEChERS technique and its degradation pattern in cabbage. Bulletin of Environmental Contamination and Toxicology, 88, 372-376. doi:10.1007/s00128-011-0468-8

[4] Wing, K.D., Sacher, M., Kagaya, Y., Tsurubuchi, Y., Mulderig, L., Connair, M. and Schnee, M. (2000) Bioactivation and mode of action of the oxadiazine indoxacarb in insects. Crop Protection, 19, 537-545. doi:10.1016/S0261-2194(00)00070-3

[5] Sakamto, N., Saito, S., Hirose, T., Suzuki, M., Matsuo, S., Izumi, K., Nagatomi, T., Ikegami, H., Umeda, K., Tsu- shima, K. and Matsuo, N. (2003) The discovery of pyridalyl: A novel insecticidal agent for controlling lepidopterous pests. Pest Management Science, 60, 25-34. doi: $10.1002 /$ ps.788

[6] Sakamoto, N., Umeda, N., Umeda, K., Matsuo, S., Haga, T., Fujisawa, T. and Tomigahara, Y. (2005) Research and development of a novel insecticide "pyridalyl". Sumitomo Kagaku, 2005, 33-44.

[7] Lee, E.Y., Kim, D.K., Park, I.Y., Noh, H.H., Park, Y.S., Kim, T.H., Jin, C.W., Kim, K.I., Yun, S.S., Oh, S.K. and Kyung, K.S. (2008) Residue patterns of indoxacarb and thiamethoxam in Chinese cabbage (Brassica campestris L.) grown under greenhouse conditions and their estimated daily intake. Korean Journal of Environmental Agriculture, 27, 92-98. doi:10.5338/KJEA.2008.27.1.092

[8] Kim, S.W., Lee, E.M., Lin, Y., Park, H.W., Lee, H.R., Riu, M.J., Na, Y.R., Noh, J.E., Keum, Y.S. and Kim, J.H. (2009) Establishment of pre-harvest residue limit (PHRL) of insecticide bifenthrin during cultivation of grape. Korean Journal of Pesticide Science, 13, 241-248.

[9] FAO and WHO (2006) Pesticide residues in food 2005. Food \& Agriculture Organization, 623-624.

[10] Hrousková, S., Andraščiková, M., Abdel Ghani, S.B. and Purdešová, A. (2012) Investigation of levels and fate of pyridalyl in fruit and vegetable samples by fast gas chromatography-mass spectrometry. Food Analytical Methods, in press. $\underline{\text { doi:10.1007/s12161-012-9508-1 }}$ 